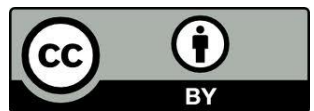

\title{
EDIFICANDO UM CONGÁ PARA A MEMÓRIA JOINVILENSE: AS RELIGIÕES MEDIÚNICAS PRESENTES NA GESTÃO DA MEMÓRIA DE UMA CIDADE
}

\author{
Edifying one conga for Joinville memory: mediumship religions present in the memory \\ management of a city
}

Artur Cesar Isaia Universidade Federal de Santa Catarina Professor do Departamento de História e do Programa de Pós-Graduação em História Bolsista do Programa de Bolsas Universitárias de Santa Catarina - UNIEDU e-mail: arturci@uol.com.br

Elaine Cristina Machado Universidade Federal de Santa Catarina Doutoranda do Programa de Programa de Pós-Graduação em História e-mail: elainemachado.ecm@gmail.com

RESUMO: Este texto expõe problematizações acerca da (in)visibilidade da umbanda em Joinville e da pluralidade religiosa presente na cidade. A partir da segunda metade do século XX sobressai em Joinville uma preocupação de preservar o passado da cidade por meio da guarda de documentos e das edificação de espaços de guarda da memória da cidade. No desejo de preservar o passado há uma operação de seletividade em movimento e em meio a esse investimento residem ações que conjugam, somam e subtraem aquilo que deve e merece ser guardado. Assim, ao investigarmos a composição e a dinâmica do campo religioso em Joinville nos deparamos com um exercício de enquadramento e cerceamento das religiões mediúnicas residindo em meio as preocupações de preservação da memória de uma cidade que celebra seu pioneirismo germânico.

Palavras chave: Memória, Religiões mediúnicas, Umbanda.

ABSTRACT: This paper exposes problematizations about the (in) visibility of Umbanda in Joinville and religious plurality in this city. From the second half of the twentieth century stands in Joinville a concern to preserve the city's past, keeping the documents, and the building guard spaces for the city's memory. The desire to preserve the past, there is a movement in selectivity operation and in the midst of this investment lie actions combine, add and subtract what should and deserves to be saved. Thus, to investigate the composition and dynamics of the religious field in Joinville we face an exercise framework and curtailment of mediumistic religions residing amid the memory preservation concerns of a city that celebrates its German pioneer.

Keywords: Memory, Psychic religion, Umbanda. 


\section{Explorando a composição do campo religioso em Joinville}

Reconhecer outros itinerários em meio ao campo religioso de Joinville é uma tarefa, no mínimo, sedutora. A cidade que se localiza ao norte de Santa Catarina teve sua fundação oficial em 1851, quando na condição colônia ${ }^{1}$ passou a receber sucessivas levas de imigrantes vindos da Europa. Os imigrantes que se fixaram na recém-fundada Colônia Dona Francisca, atual cidade de Joinville, eram provenientes de regiões hoje pertencente à Alemanha, Suíça e Noruega. ${ }^{2}$

Os luteranos eram maioria entre os imigrantes que aqui desembarcaram, embora o catolicismo fosse a religião oficial do Estado brasileiro até o ano de 1889. Além dos recém-chegados imigrantes europeus, já estavam estabelecidos nessa região lusobrasileiros que em sua maioria professavam o catolicismo.

A presença e a forte atuação dessas duas denominações religiosas foram fundamentais na organização e orquestração da vida pública e privada da cidade. Algumas das dificuldades encontradas por esses imigrantes como o idioma, o clima, o solo e a ausência de infraestrutura eram de domínio público, pois ficou bastante nítido que os colonos imigrantes encontraram no Brasil uma realidade bastante contrastante em relação aquela anunciada nas propagandas das companhias colonizadoras lá na Europa. Alguns desses obstáculos foram amenizados e contornados graças à atuação dos líderes religiosos nas comunidades onde estavam inseridos.

Em pesquisa desenvolvida pelo Instituto do Patrimônio Histórico e Artístico Nacional - IPHAN, desenvolvida como parte integrante do projeto "Roteiros Nacionais de Imigração", concluiu-se que,

\footnotetext{
Em um século de imigração, estima-se que o Brasil tenha recebido um número aproximado de 5 milhões de imigrantes, a grande maioria nos estados do sul, multiplicando várias vezes o seu contingente populacional. Proporcionalmente, o grupo de alemães é o mais representativo, chegando a cerca de $40 \%$ de descendentes no estado. Seguem-se os descendentes de italianos, que somam um total aproximado de $30 \%$ da população. Os poloneses representam uma fatia em torno de $5 \%$ dos descendentes de imigrantes. É importante ressaltar que alguns pesquisadores consideram subquantificados os dados oficiais a respeito da imigração polonesa ao Brasil, vistas as complicações políticas e territoriais daquele país à época do fluxo
}

\footnotetext{
${ }^{1}$ A Colônia Dona Francisca foi um empreendimento particular administrado pela Companhia Colonizadora de Hamburgo. Foi fruto do incentivo do governo imperial brasileiro de atração de mão-de-obra imigrante e de ocupação de áreas ainda pouco habitadas. Das vinte e cinco léguas quadradas que o príncipe de Joinville recebeu por ocasião de seu casamento com princesa Francisca Carolina, irmã de D. Pedro II, oito foram destinadas ao comércio de terras para compor a nova colônia de imigrantes europeus.

${ }^{2}$ FICKER, Carlos. História de Joinville: subsídios para a crônica da Colônia Dona Francisca. Joinville: Impressora Ipiranga, 1965.
} 
migratório, que faziam com que os imigrantes poloneses (a eles somados os ucranianos, considerados minoria étnica) fossem, em muitos casos, quantificados como russos, austríacos ou mesmo alemães. (IPHAN. p. 115)

Essas informações nos ajudam a vislumbrar o tamanho, a importância e as dimensões desses empreendimentos chamados de colônias, especialmente aqueles que ocuparam um papel singular como foi o caso da Colônia Blumenau e Dona Francisca ${ }^{3}$, dado ao número de imigrantes que foram alocados nessas colônias e na extensão territorial que as compreendia.

Ao realizar uma análise sobre o processo de imigração e colonização empreendido especialmente no Sul do Brasil do século XIX, Geralda Seyferth sublinha:

\begin{abstract}
A política de colonização privilegiou a localização de europeus, sendo conjuntural a primazia dos suíços e alemães na primeira fase do processo de implantação de colônias; e a distintividade estava baseada na qualificação de agricultor. [...]. A imigração alemã começou a ser considerada inconveniente ao país quando começaram os conflitos - principalmente aqueles motivados por razões religiosas ou étnicas - e ficaram evidentes as distintividades atribuídas a pertencimento nacional. (SEYFERTH, 2002. p.128)
\end{abstract}

Estas distensões entre aqueles que já estavam estabelecidos no Brasil e aqueles que chegavam deixaram bastante evidentes os descompassos e lacunas do projeto de ocupação e colonização estimulado e sob concessão do governo imperial brasileiro. Ao imigrante, ao estrangeiro, que se estabeleceu no Brasil do século XIX foi legado a condição restritiva de direitos de cidadãos.

A transparente distância entre os direitos dos brasileiros e os deveres dos imigrantes e a não rara ausência do Estado brasileiro, somados ao hiato gerado pelo sentimento de não pertencimento ao Brasil enquanto nação levou a manifestações públicas de defesa de um universo balizado pelos valores da germanidade, um espaço romantizado de recriação de um modo de vida alemão, chamado de Deutschtum ${ }^{4}$.

A retroalimentação do sentimento de pertença e a reelaboração de uma leitura de mundo que conjugasse aquilo que ficou pra trás, no outro continente, com o por vir deixaram marcas aparentes. Essas marcas nos permitem mapear os investimentos

\footnotetext{
${ }^{3}$ A Colônia Dona Francisca é elevada ao status de cidade, por meio da lei provincial no 842 de 03 de maio de 1877 .

${ }^{4} \mathrm{O}$ conceito de Deutschtum foi bastante explorado pela antropóloga Giralda Seyferth, principalmente em seu estudo intitulado "A Dimensão Cultural da Imigração", publicado em 2011.
} 
dispensados a essa nova configuração social experimentada pelos imigrantes que compuseram as colônias e seus descendentes.

A imprensa foi um vetor que teve ação muito eficaz na maneira em que o modo de vida alemão foi se compondo. Em 1862 foi lançado, na então Colônia Dona Francisca, um jornal impresso no idioma alemão chamado Kolonie Zeitung. ${ }^{5}$ No editorial de seu número piloto Ottokar Doerffel sublinha que é por meio da índole e do espírito germânico que o respeito e o afeto a nova pátria será conquistado, porém isso não deveria implicar na perda da antiga pátria.

O trecho abaixo, extraído desse editorial, nos permite acessar a leitura de um imigrante alemão acerca do lugar em que ele e seus pares estavam inseridos, mirando o lugar que estavam dispostos a construir:

\footnotetext{
"Pátria![...]

A verdadeira pátria, com as suaves recordações de nossa juventude, com tudo aquilo que se nos tornou caro pela educação e pelo hábito do dia-a-dia nós a deixamos longe [...] E a nova terra, na qual construímos o nosso lar e à qual ligamos toda a nossa existência? Esta nova terra ainda não se tornou pátria para nós.

[...] Realmente embaraçosa e desalentadora situação a nossa, quando - feito apátridas - não sabemos, por assim dizer, a quem pertencemos!

Mas não, caros leitores! Exatamente esta nossa situação poderá se tornar bastante feliz, se nós mesmos não falharmos. Com vontade firme e perseverança conseguiremos reatar as relações com a velha pátria,

[...] torná-las cada vez mais vivas e assim ampliar, por assim dizer, a velha pátria até nós - não no espaço, decerto, mas espiritualmente. ${ }^{6}$
}

Segundo essa perspectiva o desafio era duplo: colaborar na construção de uma nova pátria que estava sendo aos poucos desbravada por esses imigrantes e construir uma nova cidade, deixando sempre sobressalente o orgulho de ser alemão. Assim, era preciso que esses imigrantes incorporassem esse desafio. Era preciso realizar uma operação de transformação. Transformar o desafio em desejo! É em meio a essa operação que instituições reguladoras da vida social e pública passaram a agir, especialmente as igrejas. No caso de Joinville esse papel foi desempenhado essencialmente pela igreja católica e luterana.

O estabelecimento e a operação de uma lógica de controle social cristã católica/luterana alcançavam os cuidados com o corpo, a mente e o espírito. Trouxeram alento as angústias, as saudades, as crises e a todo e qualquer tipo de adversidade. Essas

${ }^{5}$ O Kolonie Zeitung foi criado por Ottokar Doerffel circulou até o ano de 1942 e era o periódico mais lido entre os joinvilenses.

${ }^{6}$ Jornal Kolonie Zeitung, 20/12/1862. Tradução de Elly Herkendorf (Arquivo Histórico de Joinville). 
denominações religiosas desempenhavam o papel de ensinar as primeiras letras e ensinar o português aos colonos, atuavam nos cuidados com os enfermos, nos hospitais por elas mantidos, e trabalharam no fortalecimento e ampliação de seu rebanho por meio das suas doutrinas e catequeses.

Embora a religião oficial do Estado brasileiro até o ano de 1889 fosse a católica algumas concessões foram permitidas em áreas de colonização. Na Colônia Dona Francisca isso foi possível porque haviam distancias que eram alargadas pelo idioma e pela falta de infra-estrutura que oferecesse um conforto mínimo.

Atualmente, um dos periódicos com grande circulação na cidade é o Jornal A Notícia. A edição comemorativa pela ocasião do aniversário de 150 anos de Joinville ${ }^{7}$ chama a atenção para a atuação das igrejas cristãs na cidade, dando destaque ao espaço ocupado pela Igreja Luterana. Segundo a matéria:

Cidade é o maior pólo luterano do continente Maior religião de Joinville divide o espaço da fé com outros 20 credos

Ao completar um século e meio de história, Joinville se apresenta como uma cidade de fé cristã. Apesar de haver mais de 20 diferentes religiões presentes na cidade, são as igrejas cristãs, especialmente evangélicas, luteranas, católicas e neopentecostais, que têm maior presença, seja pelo número de templos construídos, seja pela quantidade de fiéis em suas manifestações.

$[\ldots]$

A mais antiga é a Igreja Evangélica de Confissão Luterana do Brasil (IECLB), que nos 150 anos da cidade também comemora o fato de a região ser o maior pólo latino-americano de luteranos, o que é reconhecido inclusive pela Igreja Católica.

A força com que se constituiu a igreja luterana em Joinville e o alcance sobre decisões e encaminhamentos tomados na econômica e política da cidade sempre tiveram muito peso. A data de constituição da primeira comunidade luterana em Joinville é de 1851, data de fundação oficial da Colônia Dona Francisca. Porém, é preciso sublinhar que para exercitar seu credo os luteranos tiveram que contornar o que estava estabelecido na Constituição Brasileira de 1824.

De acordo com o artigo $5^{\circ}$ da Constituição Brasileira de 1824:

\footnotetext{
7 Jornal A Notícia. 09/03/2001.
} 
A Religião Catholica Apostolica Romana continuará a ser a Religião do Imperio. Todas as outras Religiões serão permitidas com seu culto domestico, ou particular em casas para isso destinadas, sem fórma alguma exterior do Templo.

Em Joinville os templos religiosos luteranos abrigavam funções que iam além das celebrações religiosas regidas pelos pastores. Essas casas de orações também serviam de espaço de orientação pessoal, de espaço de ensino e de sociabilidades.

Contudo faz-se necessário sublinhar que os conflitos gerados entre católicos e luteranos foram sentidos em toda Província de Santa Catarina, pois as igrejas, em grande medida, assumiam o papel do Estado. Porém, as decisões tomadas pela Igreja Católica tinham peso maior, dada a sua condição de religião oficial do Estado brasileiro. Sua postura combativa em relação a presença de luteranos e do papel desempenhado pelos pastores junto a comunidade em que estavam inseridos era transparente e contundente.

Conforme constata João Klug (1998. p. 126), “(...) o zelo pela homogeneidade religiosa, muitas vezes revela-se mais forte que a homogeneidade étnica."

Ao investigar como o luteranismo e a germanidade se chocam com o catolicismo luso-brasileiro e com o catolicismo de imigração João Klug (1998) apresenta em meio a sua análise um exemplo de como a Igreja Católica resolvia seus conflitos em consonância com o Estado, por força do padroado. Conforme anuncia Klug (1998),

\begin{abstract}
podemos citar a tensão gerada na colônia D. Francisca, em 1854, quando as autoridades da Província aplicaram com rigor o artigo 81, da Lei Escolar daquele ano, através da qual o professor Milner, por ser evangélico, ficava impedido de prestar exames para o cargo de professor público. Em contrapartida o Pe. Carlos Boegershausen foi nomeado professor vitalicio, sem ter prestado qualquer concurso. Não se questionava a capacidade do Pe. Boegershausen que, aliás, era bem quisto pela população evangélica daquela colônia, mas sim a forma como se conduziam as coisas, em relação a esta população que era majoritária.
\end{abstract}

Embora os números de crianças freqüentadoras das salas de aula do Pe. Carlos dessem conta de que havia uma maioria luterana o ensino estava sob os cuidados de um pároco católico e acontecia nas dependências da Igreja Católica. ${ }^{8}$ Esse quadro conflitante instalado em Joinville nos possibilita entender algumas das disputas presentes neste campo religioso. Para além dessas disputas pendulares envolvendo

${ }^{8} \mathrm{O}$ fato das aulas serem ministradas nas dependências da Igreja Católica não resultava de uma imposição do Estado ou da Igreja Católica, mas de uma situação gerada a partir da impossibilidade de se usar o prédio da escola, pois o mesmo havia ruído. 
católicos e luteranos é possível enxergar que aquela imagem de unidade étnica germânica apresenta fissuras onde se instalam não só as reivindicações pelo direito de ensinar as primeiras letras, mas também esteve em jogo uma disputa pelo domínio de um mercado religioso.

Dado ao peso dessas disputas envolvendo o campo religioso em Joinville e a postura adotada pelo Pe. Carlos, considerado por muitos luteranos como um conciliador, os luteranos encontraram espaço para fundar em 1866 a escola evangélica alemã de Joinville. Assim, tanto católicos quanto luteranos encontraram espaço para educar os jovens sob os seus princípios religiosos. Contudo, cabe sublinhar que dado ao rigor e a austeridade presentes no ensino luterano os jovens eram vistos como promissores empreendedores.

Ao analisar a relação entre política e luteranismo em Joinville Filipe Ferrari (2015) problematiza a origem germânica e protestante de boa parte dos imigrantes que se estabeleceram em Joinville com a celebração da imagem de "cidade do trabalho". Ao tecer essa analise Ferrari (2015) chama para sua discussão os estudos produzidos por Apolinário Ternes (1984) em que explica o empreendedorismo presente na cidade sob a ótica protestante. Segundo Ferrari (2015. p.17),

\footnotetext{
No caso de Joinville, a origem germânica e protestante de boa parte de seus imigrantes ajuda a reforçar o ideal de "Cidade do Trabalho", mítica chamada por Apolinário Ternes $(1984$, p. 37) de "irresistível vocação" para trabalhar. Para Ternes (1984, p. 100), somente "a firmeza psicológica que explica a permanência de quase todos os 118 emigrantes alemães em Joinville”. Esses aspectos são creditados por Ternes (1984, p. 162) aos imigrantes europeus, no qual ele frisa "temos ainda que destacar, que o processo econômico estará sempre intimamente relacionado com o conteúdo da cultura alemã" em especial àqueles que vinham de uma tradição protestante. Estes chegavam ao norte catarinense imbuídos de um "espírito liberal e democrático dos alemães que para cá vieram", além de estarem "sob o espírito da Reforma, sob uma ótica capitalista, de que o trabalho gera capital e que este se transforma, gerando mais riquezas" (TERNES, 1984, p. 185 e 191).
}

A conjugação de duas lógicas cristãs (católica/luterana) de ver, ler, estar e interpretar o mundo colaboraram para que Joinville fosse, e em grande medida para que ainda seja, uma cidade que se permitiu receber ao longo de sua trajetória alguns epítetos que enfatizam as virtudes do modelo de colonização e dos colonizadores que a cidade recebeu. Cidade ordeira, Manchester catarinense, cidade laboriosa, cidade da ordem foram alguns dos adjetivos empregados para definir Joinville. Esses títulos são 
utilizados de maneira recorrente e creditam aos imigrantes que aqui chegaram todos os resultados alcançados com seu empreendedorismo pioneiro.

Essa leitura sobre os motivos que fizeram de Joinville um grande pólo industrial e a cidade mais populosa de Santa Catarina costuma estar recorrentemente presente. Esta anunciação acerca da cidade e sua história se apóiam em uma memória branca, de raízes européia, cristã e germânica que é amplamente celebrada.

É nesse hiato que reside a curiosidade que moveu este estudo: há espaço para outras práticas e crenças religiosas que não operem exclusivamente dentro do universo católico ou luterano em Joinville? Como uma cidade que se esforça para manter vivo seu Deutschtum, que reside no século XIX, lidou com a pluralidade religiosa presente no século XX?

Um dos investimentos mais eficazes utilizados para manter vivo esse modo de ser alemão foi a constante rememoração da colonização da cidade. Essa imagem foi composta por tonalidades que valorizavam qualidades consideradas inerentes aos alemães que aqui se estabeleceram. Tais atributos sublinhavam a entrega disciplinar ao trabalho e a fé cristã como elementos essenciais para que as pessoas alcançassem a prosperidade.

\section{Guarnecendo a memória dos antepassados germânicos}

“Arquivai, Arquivai, sempre restará algo!” (NORA, Pierre. Les

\section{Lieux de Mémoire I. p.XXVIII)}

O projeto de reavivamento do passado de Joinville, a partir da segunda metade do século $\mathrm{XX}$, foi alimentado essencialmente pela manifestação pública de valorização da memória daqueles cujo capital simbólico ou financeiro encontrou lugar para celebrar sua imagem e semelhança. Era o momento de retribuir todos os investimentos e expectativas que os imigrantes vindos da Europa, a partir de meados do século XIX, depositaram na cidade. ${ }^{9}$

O imigrante, cuja memória foi eleita e legada a celebração era o imigrante alemão. Aquele imigrante reconhecido pela sua austeridade, pela sua fé religiosa, pela

\footnotetext{
${ }^{9}$ Sobre as comemorações do centenário de Joinville ver: SILVA, 2008.
} 
fé no ofício que desempenhava e na cidade que ajudou a construir. Embora outras nacionalidades e grupos tivessem vivido na cidade, esses sujeitos tiveram suas origens enquadradas e definidas a partir de uma única denominação: o alemão. ${ }^{10}$

As comemorações de aniversário da cidade sempre trouxeram consigo um caráter pedagógico, buscaram construir junto aos moradores da cidade uma leitura linear de sua história. Sem considerar os diferentes tempos da cidade, as diferentes narrativas e as múltiplas formas de ver e ler o passado.

As inúmeras preocupações e investimentos, relacionados diretamente ao campo sentimental, reavivadas especialmente a partir de meados do século XX conduziram uma série de ações que resultaram na criação de espaços de memória em Joinville. $\mathrm{O}$ apego ao passado, àquilo que comumente já não circula ou está em uso e o sentimento de nostalgia ocupa e canaliza as energias necessárias à implantação de espaços de memória.

Entre os espaços que figuraram entre os mais acionados e que receberam mais atenção do poder público e da elite pensante da cidade estão o Museu Nacional de Imigração e Colonização ${ }^{11}$ e o Arquivo Histórico de Joinville.

Este museu foi criado para tratar das memórias da imigração e colonização do Sul do país, porém na prática dedicou-se a ressaltar as contribuições dos pioneiros imigrantes que colonizaram Joinville. Já o Arquivo Histórico de Joinville abertamente, por meio de sua lei de criação, ${ }^{12}$ buscou defender e perpetuar as memórias e as histórias dos antepassados imigrantes que povoaram e construíram esta cidade.

Um dos sujeitos mais atuantes na guarda e defesa das memórias citadas acima foi Adolfo Bernardo Schneider. Ele foi um historiador autodidata bastante empenhado em recolher, guardar e compor narrativas históricas oficiais de Joinville.

Ao pensar os embates travados no processo de patrimonialização de uma antiga estação ferroviária da cidade a historiadora Ilanil Coelho (2011) assim sublinha a atuação de Adolfo Bernardo Schneider:

Sob sua influência, foi elaborada a lei de criação do Arquivo Histórico de Joinville (1972), tendo sido nomeado o primeiro diretor. Participou

\footnotetext{
${ }^{10}$ Um estudo desenvolvido pelo historiador Dilney Cunha intitulado "Suíços em Joinville: o duplo desterro" apresenta subsídios acerca do número de imigrantes suíços que desembarcaram no Brasil e foram conduzidos á Joinville. Segundo Cunha "os suíços chegaram mesmo a constituir a maioria da população da colônia" [Dona Francisca].

${ }^{11}$ Sobre a criação do Museu Nacional de Imigração e Colonização ver: MACHADO, 2013.

${ }^{12}$ Joinville. Lei ${ }^{\circ} 1182$ de 20 de março de 1972.
} 
ativamente da fundação do Museu Casa Fritz Alt. (1985), do Museu Arqueológico de Sambaqui (1963) e do Museu Nacional de Imigração e Colonização (1957). Pouco antes de morrer explicou as razões do seu envolvimento ativo nesta área: Joinville teria estagnado após a implantação da "legislação getuliana" do final dos anos 1930, bem como após a industrialização "galopante" que fez afluir à cidade "os operários do interior". Imperioso foi o "reavivamento cultural” (FUNDAÇÃO, 1996, p. 8) urbano por meio do recolhimento e guarda de documentos e a fundação de museus que expusessem a história $e$ a identidade dos joinvilenses. Portanto, Schneider produz sentidos para o patrimônio urbano baseando-se não apenas na operação de equivalência entre memória e história, mas também na importância do patrimônio cultural como marcação para uma identidade concebida como a identidade da cidade. (Grifos nossos)

Sob a justificativa e a expectativa do "reavivamento cultural" de uma cultura fragilizada $^{13}$ e opaca e que merecia ser retomada Adolfo Bernardo Schneider, combatendo os efeitos da "legislação getuliana" e da chegada de migrantes na cidade que trouxeram consigo outros hábitos culturais e outras formas de ler, ver e viver o mundo, contribuiu ativamente na criação e manutenção da constante rememoração de uma história de Joinville erigida pelos atos de seus heroicos imigrantes pioneiros.

Outra profissional que se empenhou na busca, recolhimento, acondicionamento e tradução de documentos que pertencem ao acervo do Arquivo Histórico de Joinville foi Maria Thereza Böbel ${ }^{14}$. Maria Thereza Böbel era de família teuto-brasileira e também fazia coro as necessidades de se preservar e proteger a memórias dos antepassados imigrantes que vieram para a cidade. Ao conceder uma entrevista oral ao historiador Diego Finder Machado, por ocasião de uma pesquisa realizada sobre o Museu Nacional de Imigração e Colonização, com texto publicado no Caderno de Iniciação à Pesquisa Cientifica da Univille (v.6, Novembro/2004), Maria Thereza Böbel explica a importância de se preservar a cultura germânica, seu passado e o Deutschtum aqui cultivado:

[...] Tem gente que chega de fora, que não tem raiz nenhuma aqui e acha que vem e pode impor a sua cultura, o seu modo de viver, de serem, os seus costumes [...] tem que respeitar um pouquinho o quê que Joinville era. (MACHADO 2004. p.212) (grifo nosso)

\footnotetext{
${ }_{13}$ Dada as ações e ressonâncias da Campanha de Nacionalização instituída pelo governo de Getúlio Vargas no final da década de 1930 e início dos anos 1940 que implicou em uma série de imposições e medidas para combater o perigo alemão. Essas ações resultaram em perseguições, silenciamentos, torturas e prisões de muitos imigrantes que resistiram ou não conseguiram de imediato cumprir a sentença que embasou essa campanha: o abrasileiramento. A esse respeito ver: Coelho (2000) e Silva (2008).

${ }^{14}$ Maria Thereza Böbel atuou também diretora do Museu Nacional de Imigração e Colonização no período de 27/04/1995 à 20/12/1996. Nomeada pela Fundação Cultural de Joinville, mantenedora do Museu, deixou o cargo por desentendimentos com a Comissão de Amigos do Museu Nacional de Imigração e Colonização.
} 
É no descompasso instalado entre uma cidade que abriga diferentes temporalidades, narrativas, leituras, sujeitos e memórias e uma cidade que deve operar a partir da reverência ao seu passado, apresentado por meio de retóricas lineares, que a ex-tradutora de alemão e ex-funcionária ${ }^{15}$ do Arquivo Histórico de Joinville emite sua sentença.

O que sobressai aqui, diante desta situação, é a composição de espaços de memória ${ }^{16}$, onde o que fica evidente é a necessidade de publicizar e partilhar narrativas que tratem da formação de uma cidade laboriosa, ordeira e próspera concebida sob a influencia do espírito alemão e da ética protestante. ${ }^{17}$

Esse desejo de memória não é um sentimento exclusivo de Joinville, em todo o país podemos observar o florescimento de ações que resultam na composição de espaços de memória e de narrativas alimentados por esta sedução.

Paira, sobretudo a partir da década de 1970, uma ansiedade pela preservação estimulada pela ameaça da perda, muito em razão do que tem sido chamado de aceleração da história, da obsolescência cada vez mais rápida de todas as coisas. Conforme enuncia NORA,

\begin{abstract}
Atualmente, em um mundo de evolução cada vez mais rápida, onde tudo passa tão depressa que cada acontecimento se reveste de um caráter histórico e já obsoleto, é evidente que o imperativo da memória - longe de designar apenas a dívida moral da lembrança - diz respeito mais fundamentalmente à ansiedade da perda. (NORA, 2003. p, 47).
\end{abstract}

Neste texto, publicado na Revista Comma em 2003, Pierre Nora discute como os arquivos mudaram de status nas últimas décadas. De lugar legado ao abando e ao esquecimento a santuário das sociedades contemporâneas. Para Nora, o arquivo está se colocando no coração da memória contemporânea e representa sua imagem material e visível.

\footnotetext{
${ }^{15}$ Maria Thereza Böbel nasceu em 1947 em Joinville e faleceu em 2005. Atuou como historiadora, pesquisadora, escritora e tradutora brasileira de alemão. Era especialista na tradução de manuscritos em letra gótica. Traduziu do alemão para o português grande parte da documentação do Arquivo Histórico de Joinville, onde começou a trabalhar em 1983. ${ }^{16}$ Neste texto citamos dois dos espaços construídos para abrigar a memória dos colonizadores joinvilenses, porém é a partir da década de 1960 que a cidade experiência a criação de outros espaços de memória. Espaços criados sob a influência de um seleto grupo composto por teuto-brasileiros, detentores de capital financeiro e intelectual. Em 1961 abre a público o Museu Nacional de Imigração e Colonização, que durante muito tempo sustentou o título de terceiro museu mais visitado do Sul do Brasil; Em 1963 é inaugurado o Museu Arqueológico de Sambaqui; Em 1972 é instituído o Arquivo Histórico de Joinville; e em 1985 se dá a fundação do Museu Casa Fritz Alt.

${ }^{17}$ Uma referência direta a publicação de Max Weber “A Ética Protestante e o Espírito do Capitalismo”, onde o autor investiga a relação existente entre certa forma de conduta econômica e suas raízes religiosas fincadas na lógica protestante.
} 
No caso do arquivo de Joinville o que observamos não foi apenas uma operação de seletividade de cunho educativo, que visou visitar e preservar a história de Joinville e a memória dos imigrantes germânicos. Recaiu sobre esse espaço o empenho para manter a linearidade de uma narrativa histórica que não permite considerar o outro, os de fora, o migrante, aqueles que "não tem nenhuma raiz aqui" e que "vem aqui e acha que pode impor sua cultura".

\section{Transpondo fronteiras}

As iniciativas visando a preservação do patrimônio documental materializadas na política de aquisição e guarda de documentos em Joinville, motivadas pelo desejo de memória, seguiu durante décadas métodos de coleta bastante dispersos. Esse processo envolveu desde campanhas públicas, coletas, até o recebimento de todo e qualquer volume apresentado aos balcões de atendimento do Arquivo Histórico de Joinville.

Os crivos, separações, descartes e classificações eram etapas posteriores a entrada desses documentos na instituição. A avaliação do patrimônio documental em Joinville seguiu durante décadas ${ }^{18}$ os critérios e valores daqueles que, com trabalho incansável, faziam de tudo para não legar ao esquecimento o passado de Joinville.

Ao celebrar a construção de um prédio próprio para abrigar o Arquivo Histórico de Joinville Elly Herkenhoff, ocupando um cargo de historiadora desde fins da década de 1970, escreve em um boletim desta instituição:

A nós cabe - exatamente hoje nesta época tão turbulenta de transformações e radicalizações - preservar os valores autênticos a nós legados, lutar por eles e transmiti-los, sempre imbuídos da sábia expressão do mestre Goethe: "O que herdaste de teus ancestrais, Conquista-o, para possuíres!" (HERKENHOFF, 1985. P.10)

O trecho pinçado do texto de Elly Herkenhoff mais uma vez reforça a aura de guardiões dos "valores autênticos" com status de herança que recaía sobre o grupo responsável por lutar e transmitir os valores que se projetavam por meio dos documentos que compunham o acervo do Arquivo Histórico de Joinville.

\footnotetext{
${ }^{18}$ A partir da década de 1990 houve uma guinada contrastante a essa realidade. A Fundação Cultural de Joinville, mantenedora do Arquivo Histórico, reestruturou seus quadros e dotou suas unidades com profissionais de carreira e com formação específica na s áreas em que atuam.
} 
Ao empreender estudo, que resultou em sua tese de doutoramento, sobre os arquivos e historiografia catarinense no século XIX Janice Gonçalves (2006), ao analisar a atuação do Arquivo Histórico de Joinville sublinha:

E, pelo que se depreende da leitura dos boletins do Arquivo Histórico de Joinville, de forma alguma a instituição procura se apresentar ou se firmar como arquivo contendo, prioritariamente, documentos da administração pública municipal. Desde o início, procurou forjar uma vocação mais próxima da de centro de documentação, voltado para a história do município e de seus moradores, embora privilegiando os registros gerados por um grupo social específico (os imigrantes de origem germânica e seus descendentes). (GONÇALVES, 2006. p.244.)

Movidos pelo espírito de conquista de um espaço e pela luta da manutenção dos autênticos valores germânicos o Arquivo Histórico, na condição de depositário do patrimônio documental de Joinville se converteu em templo, e seu sistema de seleção, classificação e acesso foram transformados em altares.

Há, em meio a esse sistema de organização documental, uma coleção de acervo bibliográfico, contendo a coleção de periódicos em língua estrangeira, que recebeu entre suas subdivisões o tema "Magia Negra (BR)", intitulado de "Macumba".

Trata-se de recorte de um periódico que circulou na Alemanha, em Nuremberg, cujo título é: Macumba ${ }^{19}$. Esses recortes traziam uma série de matérias que relatam as incursões de um jornalista, chamado Paul Von Gregor, pelas cidades de São Paulo e Rio de Janeiro. Este jornalista se dedicou a contar em seus textos todos os segredos, impressões e interpretações resultantes de seu percurso em espaços sagrados dedicados ao desenvolvimento daquilo que ele mesmo chamou de "perigosa magia negra".

Em uma dessas publicações nos deparamos com o seguinte conteúdo:

Macumba: Um relato sobre a magia negra no Brasil

A América do Sul é atormentada por uma doença em curso. Principalmente o Brasil é palco da magia negra. As igrejas do país são impotentes diante da magia perigosa da macumba. Grandes seitas secretas permeiam as cidades de São Paulo e do Rio de Janeiro, com milhares de habitantes. Os exemplos trazidos pelo nosso relato não são fantasias de uma pessoa ardente em febre. Essa misteriosa magia oriunda da selva existe tanto quanto as pessoas, nos destinos das quais ela interfere e tanto pode ser fatal, quanto benéfica. $\mathrm{O}$

\footnotetext{
${ }^{19} \mathrm{O}$ acesso a este conteúdo se deu por meio de tradução realizada pela tradutora Helena Remina Richlin. 
negro Alfredo é um dos macumbeiros dotados de estranhas forças hipnóticas. ${ }^{20}$

O conteúdo presente no trecho desta publicação nos provoca a refletir sobre uma composição da imagem do Brasil e de suas práticas culturais e religiosas. O texto classifica essas práticas religiosas como práticas nocivas, uma enfermidade que se espalha e toma conta da América Latina, onde as igrejas não conseguem alcançar, coibir e tornam-se impotentes frente a este perigo.

Ao afirmar que seus relatos não são fantasiosos e ao apontar, inclusive, um dos detentores desta sabedoria que mobilizam essas "forças hipnóticas" o autor tendenciosamente se posiciona ao centro de uma leitura combativa embalada por princípios brancos, europeus, cristãos e ocidentais.

Para além da força da mensagem trazida pelos textos de Paul Von Gregor, fomos seduzidos a pensar como esses recortes chegaram a Joinville. Mais ainda, porque esses recortes, com conteúdo em alemão e sem tradução foram selecionados para compor o acervo do Arquivo Histórico da cidade, sendo este um espaço dedicado a gestão documental relacionada à história local.

É fato, como já apontamos neste texto, que muitos documentos integrados ao acervo desta instituição deram entrada por meio do trabalho empreendido por alguns pesquisadores que estavam seduzidos por uma "cultura da memória", como denominou Andréas Huyssen. ${ }^{21}$ Entre esses documentos estão registros de terras, mapas, periódicos, passaportes, cartas e outras correspondências trocadas entre familiares e amigos de pessoas que moravam aqui com aqueles que haviam ficado na Europa, principalmente na Alemanha.

Esse quadro nos ajuda a compreender a presença desses conteúdos circulando em Joinville, também nos permite pensar a importância de guardar tais conteúdos que não estão diretamente ligados a cidade. Essa operação de seletividade supera o desejo de compor a história local e rememorar o passado, e é direcionada ao que se deve evitar no presente.

A guarda deste conteúdo e a permanência dele no acervo desta instituição vão ao encontro de um fenômeno que ocorre em todo país. Esbarra nos movimentos de fortalecimento provocados pelos congressos de espiritismo de umbanda realizados em

${ }^{20}$ O ano de publicação dessas matérias é 1961. Não foi possível identificar o nome do periódico.

${ }^{21}$ HUYSSEN, Andréas. Seduzidos pela Memória: arquitetura, monumentos, mídia. Rio de Janeiro: Aeroplano, 2000. p.14-15 
âmbito local e nacional e é reflexo das publicações, cada vez mais freqüentes, de estatutos dos centros espíritas na cidade.

No ano de 1979 um jornal de circulação local, o Jornal A Notícia ${ }^{22}$, noticiava a existência de aproximadamente duas dezenas de "tendas espíritas" na cidade. Nesta publicação o jornal anunciava a criação de mais um desses espaços sagrados em Joinville. Conforme esta matéria:

Foi inaugurada na última quinta-feira, dia de Cosme, Damião e Daum, a Tenda Espírita "Cabocla Jurema", de Idalina dos Santos Tilmann (noca), na rua Lauro Müeller, uma lateral da Uberaba, no bairro Floresta. Na inauguração houve festa, quando compareceram dezenas de crianças. A Tenda funcionará todos os sábados, a partir das 17 horas, e foi a única, entre as aproximadamente vinte, que existem em Joinville que comemorou a data de Cosme, Damião e Daum.

Notícias como essas ocupam cada vez mais as páginas dos jornais que circulam em Joinville. Essas notícias refletem diretamente as alterações que a cidade atravessa, especialmente a partir da década de 1950. Joinville experimenta grande aumento populacional, a partir da segunda metade do século XX, quando as indústrias instaladas na cidade estendem às cidades vizinhas e outras regiões do país investimentos para atração de mão-de-obra.

A expressão "tenda espírita" apresentada na matéria é um dos reflexos das negociações presentes dentro deste campo religioso. $O$ espiritismo, baseado nas decodificações e orientações de Allan Kardec, passa a somar forças por meio da Federação Espírita Brasileira - $\mathrm{FEB}^{23}$ para se distanciar de toda e qualquer prática religiosa que não se enquadre em seus parâmetros e orientações, incluindo o espiritismo de umbanda.

Na contramão desse processo, os umbandistas passam a trabalhar, especialmente após a realização do primeiro Congresso do Espiritismo de Umbanda ${ }^{24}$, para construir um projeto de identidade de religião nacional. Para edificar essa imagem a umbanda se aproxima de um parceiro com capital simbólico substancial: os espíritas kardecistas. Entre as teses aprovadas no I Congresso de espiritismo de umbanda está à defesa da umbanda como uma religião branca e brasileira. ${ }^{25}$

\footnotetext{
22 Jornal A Notícia. 03/10/1979.

${ }^{23}$ A Federação Espírita Brasileira (FEB) é uma instituição fundada em 1884 por um grupo de adeptos das doutrinas kardecistas que, no início, propõe-se como um órgão de divulgação e propaganda dessas doutrinas.

${ }^{24}$ Realizado no Rio de Janeiro em 1941.

${ }^{25} \mathrm{O}$ segundo Congresso do Espiritismo de Umbanda é realizado em 28 de Junho de 1961 e neste evento já é possível perceber um deslocamento da imagem da umbanda como uma religião de brancos, entretanto é no terceiro que essa imagem é reelaborada e
} 
Por mais que a umbanda se esforce para promover a desafricanização da sua imagem, branqueando a religião e dirigindo esforços para transformá-la na religião brasileira, faz-se necessário sublinhar, conforme assinala Barros (2012), que:

\begin{abstract}
Na umbanda, as "entidades" situam-se a meio caminho entre a concepção dos deuses africanos do candomblé e o espírito dos mortos dos kardecista. O transe na umbanda não é nem estritamente individual (como no kardecismo) nem propriamente representação mística (como no caso do candomblé), mas atualizações de fragmentos de uma história mais recente por meio de personagens tais como foram conservados na memória popular brasileira.
\end{abstract}

A leitura de Barros (2012) acerca dos limites do universo da umbanda e suas intersecções com outros universos, como o candomblé e o espiritismo, nos possibilita entender todo o dinamismo e a plasticidade ritualística e política que os praticantes da umbanda carregam consigo. $\mathrm{O}$ deslocamento da forma como a umbanda se apresentou em seu primeiro congresso, em 1941, para o terceiro evento nacional, realizado em 1973, nos oferece uma margem bem grande para que possamos fazer a leitura da flexibilidade política da umbanda. Em três décadas é possível identificar que há um deslocamento da proposta política e da maneira como a umbanda se apresenta; neste ínterim a umbanda, operando negociações dentro da própria estrutura política vigente no país, cambia do branqueamento bastante próximo aos espíritas para a reelaboração da sua imagem, assumindo-se como uma religião de grandes influências africanas.

Em Joinville, crescimento da produção industrial somado a ampliação populacional contribuiu significativamente para pluralizar ainda mais as relações tangenciadas por diferentes expectativas, valores e crenças. Além de fomentarem a recomposição de narrativas acerca de uma cidade marcada por discursos alusivos a ordem, ao trabalho, ao empreendedorismo alemão e a sua filiação religiosa cristã. Os investimentos para fazer de Joinville a cidade do trabalho contrapõem-se as transformações que a cidade passa neste período, pois se não houvesse essa preocupação por parte dos donos de indústrias e o comerciantes a cidade rapidamente se transformaria na cidade dos migrantes.

Assim, ao considerarmos que em meio às práticas cotidianas circula um exercício de enquadramento em relação à maneira de viver e ver a cidade é possível 
observar que há também um refluxo em relação a este exercício. Os resultados desses investimentos se fazem presentes nas relações partidárias, de trabalho, nos espaços de sociabilidades, nas relações de gênero, nas relações interétnicas e nas relações religiosas.

Em levantamento produzido em 1970 o censo do IBGE registrava uma população de 126.058 pessoas em Joinville. Desse total 92.049 eram católicos, 29.735 eram evangélicos, 646 eram espíritas e 2.351 foram registradas como pertencentes a outras religiões. Nesse mesmo levantamento 73 pessoas foram registradas como sem religião e outras 4 pessoas sem declaração. ${ }^{26}$

Ao tomarmos este levantamento como referência faz-se necessário considerar ainda que os números aqui apresentados foram extraídos usando a metodologia de projeções de amostragens, portanto apresentam lacunas. Estas lacunas ficam ainda mais salientes na medida em que consideramos a dilatação do campo religioso brasileiro, que a cada ano apresenta uma complexidade e uma diversidade ainda maior de denominações religiosas.

Ao discutir sobre os baixos índices dos praticantes de religiões de matriz afro no Brasil, refletida nos levantamentos do IBGE, Reginaldo Prandi (2004) sublinha que a baixa porcentagem de pessoas que se declaram pertencentes às religiões afro-brasileiras é resultante da hibridização decorrente da situação histórica que essas práticas se constituíram, resultando em um mascaramento desses números, outro fator que contribui para o escamoteio destes números é o preconceito histórico e cultural, que ainda se faz muito presente.

Outra questão que nos chamou a atenção foi a presença da expressão "outras religiões". Esta expressão foi o recurso utilizado para denominar aqueles que não se enquadram nas categorizações estabelecidas pelos levantamentos censitários. Esta categorização nos parece essencialmente sintomática em se tratando de uma cidade marcada pela invisibilização de religiões de matriz afro.

Na década de 1970, ocorreu um evento que mobilizou a membresia umbandista de Joinville. Em 1975 a imprensa local abre espaço para a divulgação do "I Congresso Joinvilense de Umbanda”. Em uma das matérias, que anuncia a cobertura do evento,

\footnotetext{
${ }^{26}$ Fonte: IBGE, Recenseamento Geral, 1970
} 
registra que mais de 2.000 pessoas estiveram presentes nos três dias de debates. ${ }^{27} \mathrm{O}$ congresso foi realizado em um dos ginásios de esportes da cidade, o ginásio de esportes Abel Schulz.

Além do expressivo número de participantes no evento a realização deste congresso no ginásio de esportes Abel Schulz é bastante sintomática, pois este espaço foi edificado em meados do século XX, para abrigar parte da programação dos festejos de comemoração do centenário de Joinville. A comemoração dos cem anos de fundação da cidade foi um marco que extrapola o peso da datação. Teve implicações simbólicas muito mais profundas. Nesta celebração a cidade foi mobilizada a sepultar os traumas causados pela Campanha Nacionalizadora de Getúlio Vargas.

A organização dos umbandistas em Joinville evidencia a disputa presente em meio ao campo religioso na cidade. Esta disputa é composta pela oferta de serviços religiosos, pela defesa de um capital simbólico, pela publicação de estatutos que dão sustentação legal a essas casas e pela mobilização de um grupo sensível e envolvido com essas práticas.

Um dos encaminhamentos do "I Congresso Joinvilense de Umbanda" que apontam para a disputa de território e fortalecimento deste grupo foi a eleição de membros de uma diretoria e instalação oficial da "União Municipal Umbandista de Joinville”. Este congresso teve implicações bastante positivas, pois a imprensa foi mobilizada na divulgação e cobertura do evento, o que em princípio confere um saldo positivo à articulação do grupo envolvido.

Como desdobramento deste movimento que surge na década de 1970 e é ampliado na década de 1980, Joinville sedia mais dois congressos de espiritismo de umbanda. O primeiro evento intitulado "Congresso Nacional de Umbanda" realizado entre os dias 20 e 21 de setembro de 1981, promovido pela "União joinvilense de Umbanda" e foram esperadas a participação de cerca de 3.000. Segundo a publicação do Jornal A Notícia ${ }^{28}$ neste evento participaram lideranças políticas e religiosas de todo o país. Segundo anuncia a publicação:

Entre os políticos envolvidos em umbanda deverá comparecer ao congresso o deputado federal Getúlio Dias, também estarão presentes Alceu Colares, Átila Nunes, Moab Caldas, Tancredo de oliveira, primaz da umbanda do Rio

\footnotetext{
${ }^{27}$ Jornal de Joinville 30/11/1975
}

${ }^{28}$ Jornal A Notícia 06/06/1981. 
de Janeiro, Candido de Frota Mello (primaz da umbanda de São Paulo) além de presidentes das federações de umbanda, conselhos espirituais e o presidente do Superior Órgão Espiritual do Brasil.

O outro congresso foi chamado de "10 Congresso de Umbanda da Federação Espírita de Santa Catarina". Este congresso contou com a participação de aproximadamente 1.200 pessoas e também foi realizado no Ginásio de Esportes Abel Schulz. A cobertura do evento ocupou a capa do Jornal A Notícia do dia 21 de abril de 1987. A proposta norteadora do evento foi expor a união e a articulação dos umbandistas de todo o estado. Segundo a matéria:

\begin{abstract}
Médiuns de todo o estado mostram a união da umbanda.
Mais de 1.200 pessoas prestigiaram, na tarde de ontem, no ginásio Abel Schulz, em Joinville o $1^{\circ}$ Congresso de Umbanda realizado pela Federação Espírita de Santa Catarina. Cerca de 350 médiuns de todo o estado participaram do encontro, que teve como objetivo principal mostrar ao povo que a Umbanda está unida. Um altar com a imagem de São Jorge, na umbanda representa Ogum, foi montado dentro do ginásio onde os pais-desanto prestaram suas homenagens e deram passes aos presentes. Várias autoridades também estiveram prestigiando o evento. ${ }^{29}$
\end{abstract}

Soma-se a esses dois congressos que ocorreram na década de 1980, ainda, um evento dedicado aos "Pretos Velhos", entidade da umbanda que comumente se manifesta em médiuns de todas as casas. O evento foi realizado no Centro Social do bairro Itaum, também localizado na zona sul de Joinville. A "Festa Arriada de Pretos Velhos" foi organizada conjuntamente pela Federação dos Espíritas e Umbandistas de Santa Catarina e a União joinvilense de Umbanda e Candomblé e contou com a participação de 150 pessoas incluindo pais e mães de santo, ialorixás e babalorixás de Joinville. $^{30}$

Todos os eventos promovidos na cidade pela União Joinvilense de Umbanda e pela Federação dos Espíritas e Umbandistas de Santa Catarina carregaram consigo os esforços para externar os laços que fortalecem essas práticas religiosas na cidade e deixam cada vez mais aparente a fluidez do mercado religioso e de seus bens simbólicos.

Com a mobilização desta membresia cada vez mais evidente promovendo a visibilização do estriado terreno das religiões e religiosidades na cidade, há um

\footnotetext{
${ }^{29}$ Jornal A Notícia 21/04/1987.
}

${ }^{30}$ Jornal A Notícia 10/05/1986. 
exercício de enquadramento promovido por quem olha de fora na tentativa de promover um modelo explicativo para os ritos, mitos, papéis e fenômenos religiosos que orbitam em meio ao universo das religiões mediúnicas, especialmente da umbanda.

Se por um lado a imprensa local é mobilizada para divulgar esses eventos e os inclui em sua pauta dando visibilidade e fortalecendo o próprio movimento, como é o objetivo dos organizadores, por outro lado sempre há um modelo explicativo que se assenta no catolicismo, a exemplo da matéria produzida na ocasião da realização do " 1 " Congresso de Umbanda da Federação Espírita de Santa Catarina":

[...].Um altar com a imagem de São Jorge, na umbanda representa Ogum, foi montado dentro do ginásio onde os pais-de-santo prestaram suas homenagens e deram passes aos presentes. ${ }^{31}$

Outras inserções nos veículos de imprensa explicando esse universo religioso também foram feitas, a exemplo da publicação de sobre o congresso regional de umbanda de 1981.

Consta em uma das matérias de divulgação deste evento,

[...]

A diferença principal entre a umbanda e o candomblé é que a primeira é o reinado dos eguns (mortos) e a segunda acredita no reinado dos espíritos vivos da natureza, criação suprema de Lorun (Deus) e na glorificação de Oxalá (Jesus). ${ }^{32}$

(Grifos nossos).

Os esforços para explicar as crenças e práticas mediúnicas se assentam na própria trajetória dessas religiões no país, e estão situadas sempre na tensão entre ser reconhecidas e aceitas, o que implica no delineamento de táticas e estratégias ${ }^{33}$ políticas, porém também devemos considerar a predominância do catolicismo enquanto religião oficial do Estado brasileiro vigente até 1989 e como religião adotada pela maioria da população deste país, uma conseqüência direta do nosso processo de colonização.

Esta distensão entre a explicação, aceitação e a rejeição dessas religiões e religiosidades afro-brasileiras não se dá somente em terreno joinvilense, não raro as estruturas e aparatos legais brasileiros foram mobilizados, especialmente na primeira

\footnotetext{
31 Jornal A Notícia 21/04/1987

32 Jornal A Notícia 26/09/1981

${ }^{33}$ Emprestamos o sentido de tática e estratégia do historiador Michel de Certeau. Embora estes dois conceitos estejam situados em dimensões distintas, Certeau é chamado aqui, por meio de seus conceitos, para nos ajudar a compreender como o espiritismo e a umbanda empregam esforços dentro e fora de seu campo de atuação para ganharem espaço, reconhecimento e aceitação, bem como para resistir as tentativas de invisibilização de suas práticas religiosas.
} 
metade do século XX, para frear e desestabilizar o avanço e a popularização dessas práticas religiosas.

A umbanda e outras práticas religiosas, aproveitam a fenda gerada a partir da reformulação do código penal brasileiro ${ }^{34}$ para conquistar visibilidade e território. Porém, ainda existem litígios e questionamentos sobre a eficácia, a funcionalidade e liturgia do espiritismo de umbanda, questionando seus segredos e revelações, os saberes e conhecimentos.

No cenário joinvilense, além do peso da palavra que ganha forma e corpo aproveitando as alterações nas leis brasileiras, que deliberam sobre a exposição e a visibilidade dessas práticas religiosas, é preciso considerar que pesa e ainda esta vigente, a prática de vigilância e controle.

Mesmo organizados, umbandistas tiveram que enfrentar grandes embates em busca de respeito e aceitação de suas práticas religiosas. Se por um lado havia uma significativa articulação desses grupos, por outro lado a repressão e a rejeição velada e desvelada eram muito sintomáticas. Esse quadro nos oferece condições de ler e perceber as disputas presentes no complexo e plural terreno das religiões e religiosidades e que certamente não ficaram encerradas no século XX.

\section{Referenciais}

\section{Fontes consultadas}

Brasil. Constituição Política do Império do Brasil. 25 de março de 1824.

Brasil. Código penal Brasileiro, 1890.

IBGE, Recenseamento Geral, 1970

Joinville. Lei $\mathrm{n}^{\mathrm{o}} 1182$ de 20 de março de 1972.

Jornal Kolonie Zeitung, 20/12/1862. Tradução de Elly Herkendorf (Arquivo Histórico de Joinville).

Jornal A Notícia. 09/03/2001.

Jornal A Notícia 21/04/1987.

${ }^{34}$ O Código Penal brasileiro de 1890 esteve vigente até o ano de 1941. Este instrumento apresenta profundas contradições em relação a laicização do Estado, anunciada na Constituição brasileira de 1889. Especialmente no artigo 157, que trata diretamente da prática do espiritismo. Segundo rege este artigo a prática do espiritismo é considerada crime contra a saúde pública. 
Jornal A Notícia 10/05/1986.

Jornal A Notícia 26/09/1981.

Jornal A Notícia 06/06/1981.

Jornal A Notícia. 03/10/1979.

Jornal de Joinville 30/11/1975.

\section{Bibliografias}

BARROS, Sulivan Charles. As entidades "brasileiras" da umbanda. In: ISAIA, Artur Cesar; MANOEL, Ivan Aparecido (org.). Espiritismo e religiões afro-brasileiras: história e ciências sociais. São Paulo: Ed. Unesp, 2012.

CERTEAU, Michel de. A invenção do cotidiano: artes de fazer. Petrópolis: Vozes, 1994.

COELHO, Ilanil. É proibido ser alemão: é tempo de abrasileirar-se. In: GUEDES, Sandra P L. de Camargo (Org.). Histórias de (I) Migrantes: o cotidiano de uma cidade. Joinville: Univille, 2000.

Embarques e Desembarques na Estação da Memória de Joinville. In:

Revista Tempo e Argumento. Florianópolis, v. 3, n. 1, p. 74 - 95, jan/jun. 2011.

CUNHA, Dilney. Suíços em Joinville: o duplo desterro. Joinville: Letra D’Água, 2003.

FICKER, Carlos. História de Joinville: subsídios para a crônica da Colônia Dona Francisca. Joinville: Impressora Ipiranga, 1965.

FERRARI, Filipe. Os Dois Reinos de Lutero: política e luteranismo em Joinville na contemporaneidade. Dissertação (Mestrado em Patrimônio Cultural e Sociedade). Joinville: Univille, 2015. 111p.

FUNDAÇÃO Cultural de Joinville. Arquivo Histórico de Joinville. Boletim do Arquivo Histórico. Joinville, v. 14, p. 7-12, 1996.

GONÇALVES. Janice. Sombrios Umbrais a Transpor: Arquivos e Historiografia em Santa Catarina no Século XX. Tese (Doutorado em História). São Paulo, USP, 2006. $444 \mathrm{p}$.

HERKENHOFF, Elly. O Arquivo Histórico de Joinville: seus tesouros - suas deficiências - suas possibilidades. Boletim do Arquivo Histórico de Joinville - AHJ, Joinville (SC), v.2, n.6, set. 1985.

HUYSSEN, Andréas. Seduzidos pela Memória: arquitetura, monumentos, mídia. Rio de Janeiro: Aeroplano, 2000. 
IPHAN. Dossiê de Tombamento Roteiros Nacionais de Imigração: Santa Catarina. Vol 1. Brasil, 2011.

KLUG, João. Confessionalidade e etnicidade em Santa Catarina: tensões entre luteranos e católicos. Revista de Ciências Humanas Florianópolis. v.16 n.24 p.111-127 out. de 1998.

MACHADO, Diego Finder. FINDLAY, Eleide Abril Gordon. Memória e identidade: O Museu Nacional de Imigração e Colonização de Joinville e a reafirmação da identidade local. Caderno de Iniciação cientifica da Univille. V6, p., 211-213; Joinville, SC, 2004.

MACHADO, Elaine Cristina (org). Além do que se vê: Um museu para a cidade? Museu Nacional de Imigração e Colonização. Curitiba: Lisegraf, 2013.

NORA, Pierre. "Missions et enjeux des archives dans les sociétés contemporaines". In : Comma, 2003, 2/3, p 47-49. Paris: International Council of Archives, 2003.

PRANDI, Reginaldo. O Brasil com axé: Candomblé e Umbanda no mercado religioso. Estudos avançados. São Paulo, v. 18, n. 52, 2004.

SILVA, Janine Gomes da. Tempo de Lembrar, Tempo de Esquecer: as vibrações do Centenário e o período da Nacionalização: histórias e memórias sobre a cidade de Joinville. Joinville: Univille, 2008.

WEBER, Max. A Ética Protestante e o Espírito do Capitalismo. São Paulo: Martin Claret, 2002.

Recebido: $23 / 03 / 2016$

Received: $03 / 23 / 2016$

Aprovado: $30 / 05 / 2016$

Approved: 05/30/2016 